\title{
Effect on intelligence of relaxing the low phenylalanine diet in phenylketonuria
}

\author{
Isabel Smith, Martin G Beasley, Anthony E Ades
}

\begin{abstract}
A total of 599 children with phenyketonuria, who had been treated early, were followed up prospectively in order to examine the association between intellectual progress from 4 to 14 years of age and control of phenylalanine concentrations. The phenylalanine rose from around $400 \mu \mathrm{mol} / 1$ during the first four years to above $900 \mu \mathrm{mol} / 1$ by 12 years. The children were divided into two cohorts: cohort I comprised 224 children born in the United Kingdom between 1964 and 1971 and cohort II 375 children born between 1972 and 1978. In a previous study it was shown that by 4 years of age these children already had a mean intelligence quotient (IQ) over half a standard deviation below general population norms, and that IQ fell linearly as average phenylalanine concentrations rose. Multiple regression was used to estimate the size of the associations between IQ at later ages and average phenylalanine concentrations in the periods between assessments, after controlling for previous IQ and phenylalanine control, social class, type of phenylketonuria, and factors relating to diagnosis and early management. For each $300 \mu \mathrm{mol} / 1$ rise in average phenylalanine concentrations for those aged 5 to 8 years IQ at 8 years fell by $4-6$ points. This compared with a 7-10 point fall in IQ at 4 years for a similar rise in phenylalanine. After 8 years of age the association between IQ and phenylalanine control disappeared in cohort $I$ but persisted in cohort II and was significant up to 10 years of age, although the association was smaller than at 8 years.
\end{abstract}

A previous study using the records of the Phenylketonuria Register showed that, despite early treatment, children with phenylketonuria who were detected by routine neonatal screening between 1964 and 1980 had a mean intelligence quotient (IQ) at 4 years of age at least half a standard deviation below that expected in the general population. ${ }^{1}$ Intelligence was closely associated with the quality of dietary treatment during the first four years of life. Children who were treated early also showed an increased tendency to behaviour problems at school and these were more common in children with higher phenylalanine concentrations. ${ }^{2}$ The data suggest that a significant proportion of early treated children continue to suffer some degree of neurological impairment due to the persisting hyperphenylalaninaemia.

Other reports have suggested that withdrawal of treatment after 4 years of age may be associ- ated with a further decline in intelligence or in school progress. ${ }^{3-6}$ Nevertheless many older children and adolescents choose to stop treatment because the diet requires severe restrictions on natural foods and replacement of these foods with unpalatable substitutes. The present study examines the association between intellectual progress from 4 to 14 years of age and control of blood phenylalanine concentrations over the same period, taking account of events up to 4 years. The aim was to quantitate the possible risks to intellectual ability of relaxing or stopping treatment at different ages so that better advice can be given to affected subjects.

\section{Subjects and methods}

SUBJECTS

The subjects in the study were followed up prospectively by the staff of the Phenylketonuria Register using the protocol described previously. 278 This included serial blood phenylalanine concentrations, a record of the dietary intake of phenylalanine and phenylalanine-low protein substitute at each birthday, and standardised psychological assessments at $4,8,10,12$, and 14 years. Subjects were selected for the present study if they had been treated before 4 months of age, were over 10 years of age (born 1964 to 1978), and had completed the follow up protocol to 8 years of age. At the time of the study data for those aged 9 years and over was still being collected in cohort II. Children treated for less than 1 year because they proved to have mild phenylketonuria were excluded, as were those with tetrahydrobiopterin deficiency or whose mothers had phenylketonuria.

Altogether 599 subjects fulfilled the study criteria and were divided into two cohorts: those born 1964-71 (cohort I, 224 subjects) before reorganisation of the national screening programme, ${ }^{1}$ and those born 1972-78 (cohort II, 375 patients). Eighty nine children previously studied at 4 years ${ }^{2}$ were excluded from the present study because they had no valid IQ at 8 years (39 in cohort I, 50 in cohort II), usually because testing was incomplete, outside the age limits, or the test used was other than that specified. Subjects included in the study represent $53 \%$ (cohort I) and $80 \%$ (cohort II) of all known early treated subjects in the United Kingdom compared with $63 \%$ and $89 \%$ studied at 4 years. The loss of subjects between 4 and 8 years may have exerted a slight upward bias in overall IQ as children assessed at 4 but not at 8 had a lower mean IQ than those assessed on both occasions. However, the size of the bias 
was small ( $1 \mathrm{IQ}$ point in cohort I and 0.4 points in cohort II) and does not affect the interpretation of the association between the phenylalanine control and IQ.

\section{PSYCHOLOGICAL ASSESSMENTS}

IQs were measured at the age of 4 years using the Stanford-Binet (short form L-M, 1960 revision) and at 8 years using the full forms of either the Wechsler intelligence scale for children (WISC) (cohort I), or revised WISC (WISC-R) (cohort II). IQs were remeasured at 10, 12, and 14 years of age using the same procedures as at 8 years.

As discussed previously, ${ }^{1}$ in the United States and Europe, including the United Kingdom, a steady rise in population IQ scores (of approximately 0.3 points per year from the time of standardisation onwards) has been occurring for all commonly used test procedures. A method of converting IQs to standard deviation scores (IQSDS), which allows for the influence of population trends and the differences between tests, has been described and is used again here. ${ }^{1}$ As the present study was concerned with longitudinal IQ trends in the same children (rather than in succeeding generations of children) population norms have been based on the year of the first assessment at 4 years of age-that is: revised Stanford-Binet norms $=98+0 \cdot 3$ (birth year+4-1932); revised WISC norms $=100+0 \cdot 3$ (birth year+4-1947.5); and revised WISC-R norms $=102 \cdot 6+0 \cdot 3$ (birth year $+4-1972$ ). IQSDS was then calculated by subtracting the estimates of the population IQ norms from the actual IQs, and dividing by the standard deviation for the test procedure concerned (StanfordBinet 16, WISC 15, WISC-R 14).

\section{TYPE OF PHENYLKETONURIA}

The register classifies subjects as 'atypical', 'possibly atypical', or 'classical' according to peak phenylalanine concentrations during a period of relaxation in the dietary restrictions after the first birthday ( $<900 \mu \mathrm{mol} / \mathrm{l}, 900-1200$ $\mu \mathrm{mol} / 1$, and $>1200 \mu \mathrm{mol} / 1$ respectively). As so few treated subjects fell into the 'atypical' category (seven in cohort I, 20 in cohort II) for the purposes of the present study they were merged with the 'possibly atypical' group to form a single, 'non-classical' group (25 $(11 \%)$ in cohort I, $87(23 \%)$ in cohort II).

\section{DIETARY CONTROL OF PHENYLALANINE CONCENTRATIONS}

Dietary treatment was classified at each birthday according to the total recorded phenylalanine intake (strict $=<500 \mathrm{mg} /$ day or less, relaxed $=500-1000 \mathrm{mg} / \mathrm{day})$, free $=>1000 \mathrm{mg} /$ day). Stopping treatment was defined separately as the age at which the regular intake of a phenylalanine-low protein substitute ceased. Phenylalanine concentrations were categorised and plotted against time in order to estimate area under the curve, as described previously. ${ }^{12}$ Because phenylalanine values were usually measured using semiquantitative methods (which become progressively less accurate as phenylalanine concentrations rise above $1200 \mu \mathrm{mol} / \mathrm{l}$ ) all values $>1200 \mu \mathrm{mol} / \mathrm{l}$ were coded into a single category. Relatively few quantitative results recorded up to 14 years were above $1500 \mu \mathrm{mol} / \mathrm{l}$ and phenylalanine values in the top category were set at $1350 \mu \mathrm{mol} /$ 1 (the mid-point between 1200 and $1500 \mu \mathrm{mol} / \mathrm{l}$ ) for the purposes of calculating average phenylalanine values. Means were calculated for each year of life and for eight composite follow up periods: birth $-4,5-8,9-10,9-12,11-12$, 11-14, 13-14 years.

\section{STATISTICAL METHODS}

Trends in phenylalanine control, dietary intake, and IQ-SDS were examined in relation to age. The associations between IQ-SDS and dietary control at different ages were examined in a series of tables. Multiple regression was used to determine whether IQ at different ages was related to blood phenylalanine concentrations during the periods between assessments, controlling both for IQ at the beginning of the periods and the history of phenylalanine control. Also included in the regressions were social class and type of phenylketonuria (as class variables) and four factors (as continuous variables) relating to diagnosis and early management that had previously been shown to relate to IQ-SDS at 4 years (diagnostic phenylalanine concentrations, age at start of treatment, duration of phenylalanine concentrations below $120 \mu \mathrm{mol} / 1$ in first two years and birth year). ${ }^{1}$

\section{Results}

TRENDS IN DIETARY CONTROL AND IQ-SDS WITH AGE

Figure 1 summarises overall dietary trends from the start of treatment to the 14th birthday in cohorts I and II respectively. The figures show the annual percentages of children receiving a strict, relaxed, or free diet at each birthday and median blood phenylalanine concentrations (with 10th and 90th centiles) in classical and non-classical subjects separately. In cohort I dietary follow up was complete but in cohort II the trends are based on declining numbers ( 375 up to 8 years to 130 at 12 years) because only a minority of subjects had reached their 14th birthday. After 12 years there were too few subjects for analysis.

The proportion of subjects receiving a strict diet fell with increasing age. The fall was steeper in cohort $I$ in which less than $50 \%$ of subjects were receiving a strict diet at the age of 8 years and only $11 \%$ at 12 years. In cohort II $80 \%$ were still receiving a strict diet at 8 years and $40 \%$ at 12 years. Up to 4 years of age the median phenylalanine values were relatively stable at around $400-450 \mu \mathrm{mol} / \mathrm{l}$ although in cohort II, even before 4 years, median values tended to be higher in classical compared with non-classical subjects. After 4 years classical subjects in both cohorts showed a steady rise in median phenylalanine values in parallel with the relaxation of the diet; the rise was steeper in cohort I than cohort II. Non-classical subjects 

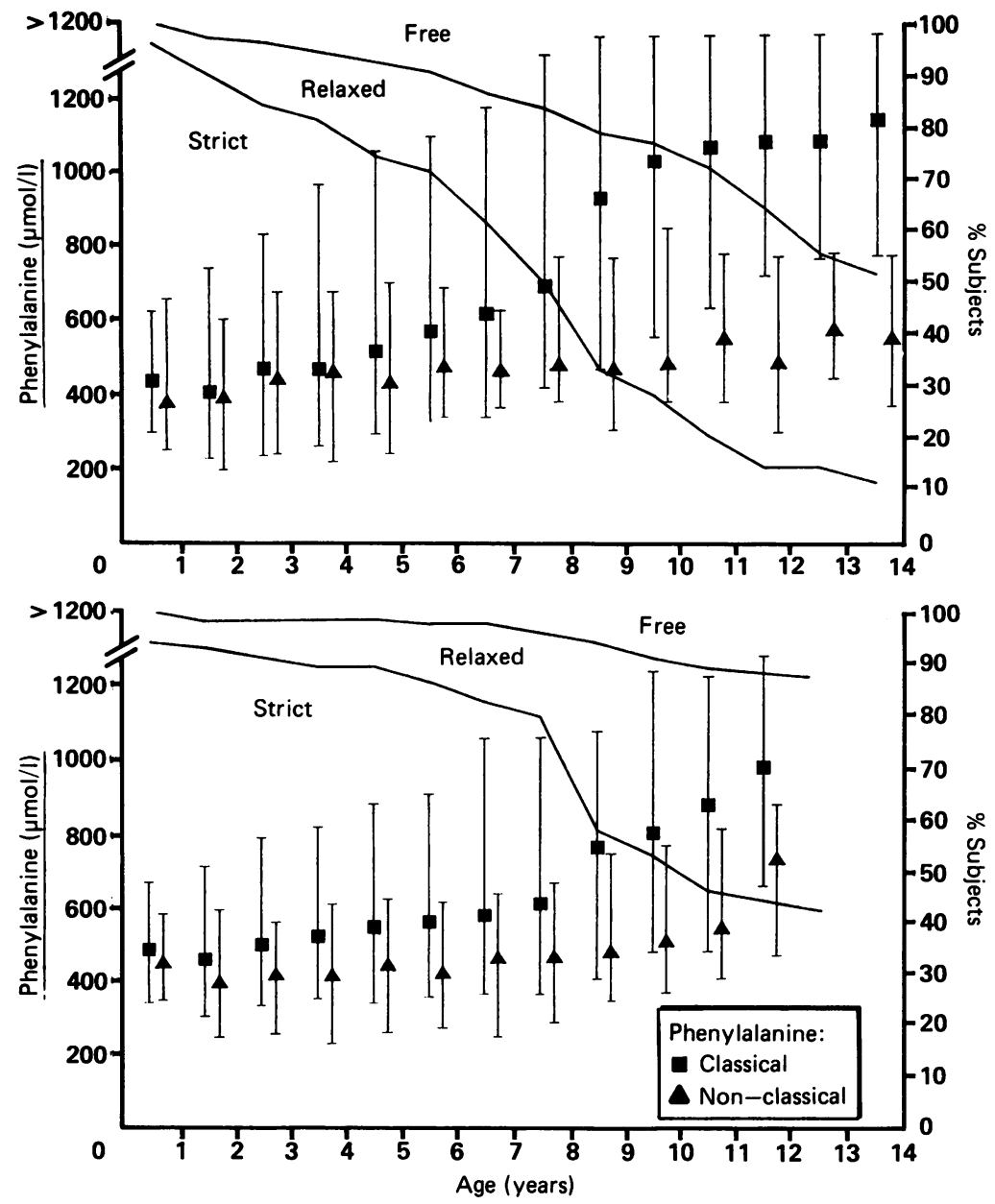

Figure 1 Trends in dietary treatment with age: upper graph, cohort I; lower graph, cohort II. Percentages of subjects receiving strict ( $<500 \mathrm{mg}$ phenylalaninelday), relaxed (500-1000 mg phenylalaninelday), or free ( $>1000 \mathrm{mg}$ phenylalaninelday) diets. Median phenylalanine concentrations (with 90th and 10th centiles) at each year of age in classical and non-classical subjects.

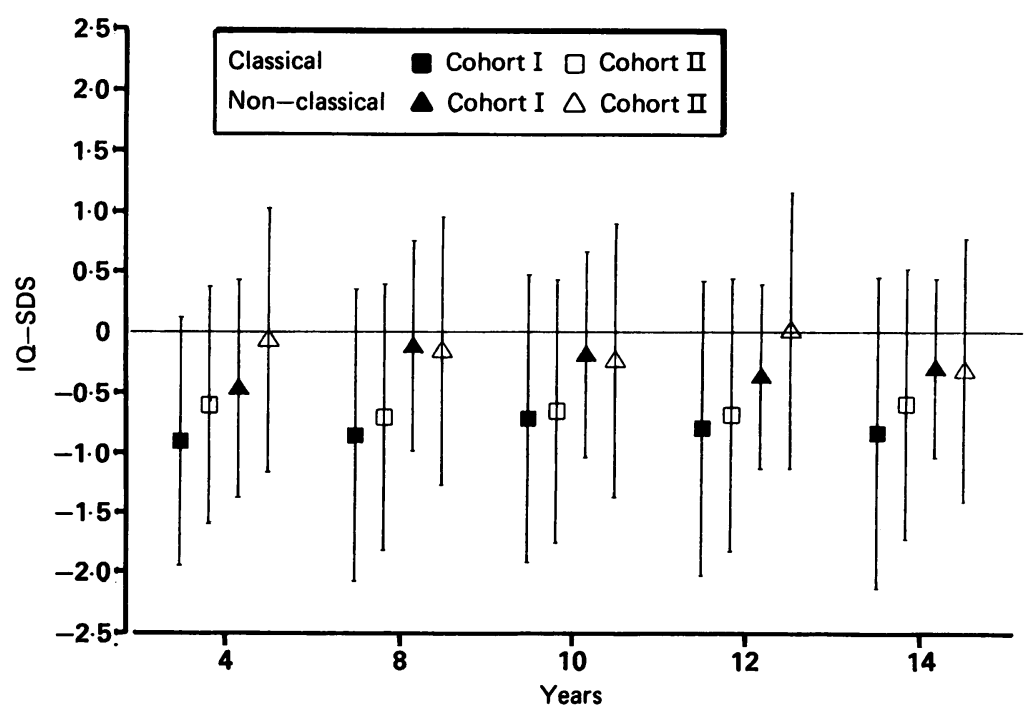

Figure 2 Trends in $1 Q-S D S$ in classical and non-classical subjects from 4 to 14 years of age; means $(S D)$ in cohorts I and II separately.

showed only a modest rise in phenylalanine concentrations with increasing age.

Between 4 and 14 years of age mean IQ-SDSs were generally very stable (fig 2). All means were negative, indicating that mean IQs were lower than expected in the general population and standard deviations centred around 1. Subjects in cohort I and those with classical phenylketonuria did worse than those in cohort II and with the classical disorder.

\section{ASSOCIATION BETWEEN IQ-SDS AND}

PHENYLALANINE CONTROL

In both cohorts and at all ages, mean IQ-SDS fell as average phenylalanine concentrations in the period preceding assessment rose. As nonclassical subjects tended to have higher mean IQ-SDSs and also had better phenylalanine control than subjects with the classical disorder, the association between IQ-SDS and phenylalanine control was re-examined in classical subjects alone; the data for 8 years of age is shown in table 1 . An inverse trend between IQ-SDS and average phenylalanine concentrations between 5 and 8 years persisted. IQ-SDS was also inversely related to earlier age at which the annual phenylalanine average concentration reached $900 \mu \mathrm{mol} / \mathrm{l}$ and children who stopped their protein substitute before 8 years did worse than the others. There were too few nonclassical subjects to permit meaningful tabulation in the same way.

As mean phenylalanine concentrations after 4 years were closely correlated with phenylalanine concentrations during the first 4 years the associations between IQ-SDS and measures of dietary control after 4 years could have arisen indirectly due to the previously demonstrated association between intellectual progress at 4 years and phenylalanine control during the first 4 years. ${ }^{1}$ In order to see whether there was any independent association between IQ-SDS at 8 years and phenylalanine control between 5 and 8 years subjects were divided into four groups according to phenylalanine control between birth and 4 years and between 5 and 8 years ( $\leqslant 600 \mu \mathrm{mol} / \mathrm{l}=$ good control, $>600 \mu \mathrm{mol} / \mathrm{l}=$ poor control) (table 2).

In both cohorts those with good control throughout the first 8 years had the least negative IQ-SDS at 8 years, those with good control in the first 4 years but poor control between 4 and 8 did less well, and those with poor control throughout the first 8 years did worst; very few subjects had poor control in the first 4 years and good control later. Examining the differences between IQ-SDS at 4 and at 8 years (table 3), in those with poor control after 4 years (whether control up to 4 years was good or poor) IQ-SDS fell between 4 and 8 years, whereas in those with good control throughout the 8 years IQSDS stayed the same or showed a rise. In both cohorts, when the changes in the poorly controlled groups were compared with the changes in the well controlled, the poorly controlled did worse by approximately -0.3 SDS ( 5 IQ points).

\section{REGRESSION ANALYSES}

The above results suggested that IQ-SDS at 8 years was independently associated with phenylalanine control between 5 and 8 years. Multiple regression analysis was used to define this asso- 
Table 1 Association between IQ-SDS at 8 years of age and dietary control (classical subjects only)

\begin{tabular}{|c|c|c|c|c|}
\hline & \multicolumn{2}{|l|}{ Cohort I } & \multicolumn{2}{|l|}{ Cohort II } \\
\hline & No (\%) & Mean IQSDS & No (\%) & Mean $I Q-S D S$ \\
\hline $\begin{array}{l}\text { Mean phenylalanine from } 5-8 \text { years }(\mu \mathrm{mol} / \mathrm{l}) \\
<400 \\
401-500 \\
501-600 \\
601-700 \\
701-900 \\
>900\end{array}$ & $\begin{array}{l}27(14) \\
41(21) \\
34(17) \\
29(15) \\
28(14) \\
39(19)\end{array}$ & $\begin{array}{l}-0.54 \\
-0.24 \\
-0.61 \\
-0.61 \\
-1 \cdot 10 \\
-1.96\end{array}$ & $\begin{array}{l}42(15) \\
65(23) \\
52(18) \\
45(16) \\
50(17) \\
33(11)\end{array}$ & $\begin{array}{l}-0 \cdot 14 \\
-0 \cdot 38 \\
-0 \cdot 47 \\
-0 \cdot 95 \\
-1 \cdot 14 \\
-1 \cdot 48\end{array}$ \\
\hline $\begin{array}{l}\text { Age annual phenylalanine became }>900 \mu \mathrm{mol} / \mathrm{l} \text { (years) } \\
>8 \\
7-8 \\
5-6 \\
3-4 \\
1-2\end{array}$ & $\begin{array}{l}124(62) \\
26(13) \\
16(8) \\
23(12) \\
10(5)\end{array}$ & $\begin{array}{l}-0 \cdot 47 \\
-1 \cdot 16 \\
-1 \cdot 62 \\
-1 \cdot 81 \\
-1 \cdot 47\end{array}$ & $\begin{aligned} 204(70) \\
35(12) \\
19(7) \\
19(7) \\
11(4)\end{aligned}$ & $\begin{array}{l}-0 \cdot 45 \\
-0 \cdot 83 \\
-1 \cdot 39 \\
-1 \cdot 73 \\
-2 \cdot 03\end{array}$ \\
\hline $\begin{array}{l}\text { Age diet stopped* } \\
>8 \text { years } \\
1-8 \\
\text { All subjects }\end{array}$ & $\begin{aligned} 157(79) \\
42(21) \\
199(100)\end{aligned}$ & $\begin{array}{l}-0.70 \\
-1.45 \\
-0.86\end{array}$ & $\begin{aligned} 272 & (94) \\
16 & (6) \\
288 & (100)\end{aligned}$ & $\begin{array}{l}-0.64 \\
-1 \cdot 76 \\
-0.71\end{array}$ \\
\hline
\end{tabular}

*Age at which administration of phenylalanine-low protein substitute ceased. The number of subjects who stopped before the 8 th year was too small to allow for meaningful subdivision.

Table 2 Association of IQ-SDS at 8 years of age and change in IQ-SDS between 4 and 8 years to mean phenylalanine concentration in $\mu$ molll from birth to 4 years and 5 to 8 years

\begin{tabular}{|c|c|c|c|c|c|c|c|c|c|}
\hline & \multirow{3}{*}{$\begin{array}{l}\text { Phenylalanine } \\
0-4 \text { years }\end{array}$} & \multicolumn{8}{|c|}{ Phenylalanine } \\
\hline & & \multicolumn{4}{|c|}{ Cohort I } & \multicolumn{4}{|c|}{ Cohort II } \\
\hline & & $\begin{array}{l}\leqslant 600 \\
\mathrm{No}\end{array}$ & $I Q-S D S$ & $\begin{array}{l}>600 \\
\text { No }\end{array}$ & $I Q-S D S$ & $\begin{array}{l}\leqslant 600 \\
\text { No }\end{array}$ & $I Q-S D S$ & $\begin{array}{l}>600 \\
\text { No }\end{array}$ & $I Q-S D S$ \\
\hline $\begin{array}{l}\text { IQ-SDS at } 8 \text { years } \\
\text { Change in IQ-SDS } 4-8 \text { years }\end{array}$ & $\begin{array}{l}<600 \\
>600 \\
<600 \\
>600\end{array}$ & $\begin{array}{r}120 \\
3 \\
120 \\
3\end{array}$ & $\begin{array}{l}-0.38 \\
-0.01 \\
+0.23 \\
+0.04\end{array}$ & $\begin{array}{l}58 \\
42 \\
58 \\
42\end{array}$ & $\begin{array}{l}-1 \cdot 12 \\
-1 \cdot 49 \\
-0 \cdot 06 \\
-0 \cdot 13\end{array}$ & $\begin{array}{r}227 \\
10 \\
227 \\
10\end{array}$ & $\begin{array}{l}-0 \cdot 24 \\
-1 \cdot 04 \\
+0.02 \\
-0.28\end{array}$ & $\begin{array}{l}88 \\
48 \\
88 \\
48\end{array}$ & $\begin{array}{l}-0 \cdot 99 \\
-1 \cdot 37 \\
-0 \cdot 30 \\
-0 \cdot 23\end{array}$ \\
\hline
\end{tabular}

Table 3 Summary of regression analyses. IQ-SDS as dependent variables with estimates (SE) of slopes of regression lines relating IQSDS to a 1000 umolll change in mean phenylalanine concentrations in period immediately before assessment

\begin{tabular}{|c|c|c|c|c|c|c|c|}
\hline \multirow{2}{*}{$\begin{array}{l}\text { Outcome } \\
\text { variable } \\
\text { IQSSDS } \\
\text { (years) }\end{array}$} & \multirow{2}{*}{$\begin{array}{l}\text { Regressor } \\
\text { variable } \\
\text { phenylalanine } \\
\text { (years) }\end{array}$} & \multicolumn{3}{|c|}{ Cohort I } & \multicolumn{3}{|c|}{ Cohort } \\
\hline & & No & Estimates $(S E)^{*}$ & p Value & No & Estimates $(S E)^{*}$ & $p$ Value \\
\hline $\begin{array}{r}4 \\
8 \\
10 \\
12 \\
14\end{array}$ & $\begin{array}{l}0-4 \\
5-8 \\
9-10 \\
9-12 \dagger \\
11-14 \dagger\end{array}$ & $\begin{array}{l}191 \\
191 \\
168 \\
167 \\
159\end{array}$ & $\begin{array}{l}-1.72(0.43) \\
-1.42(0.32) \\
+0.15(0.22) \\
+0.28(0.25) \\
+0.01(0.27)\end{array}$ & $\begin{array}{l}<0.0001 \\
<0.0001 \\
\text { NS } \\
\text { NS } \\
\text { NS }\end{array}$ & $\begin{array}{r}316 \\
316 \\
186 \\
86\end{array}$ & $\begin{array}{l}-2.10(0.41) \\
-0.88(0.29) \\
-0.52(0.20) \\
-0.58(0.38) \\
\text { Not done }\end{array}$ & $\begin{array}{c}<0.0001 \\
0.001 \\
0.02 \\
\text { NS }\end{array}$ \\
\hline
\end{tabular}

*Estimates adjusted for social class, type of phenylketonuria, IQ-SDS at previous follow up (except at 4 years), phenylalanine concentrations before 4 years, and four variables relating to diagnosis and early management (see methods).

tSimilar results were obtained for periods 11-12 and 13-14 years.

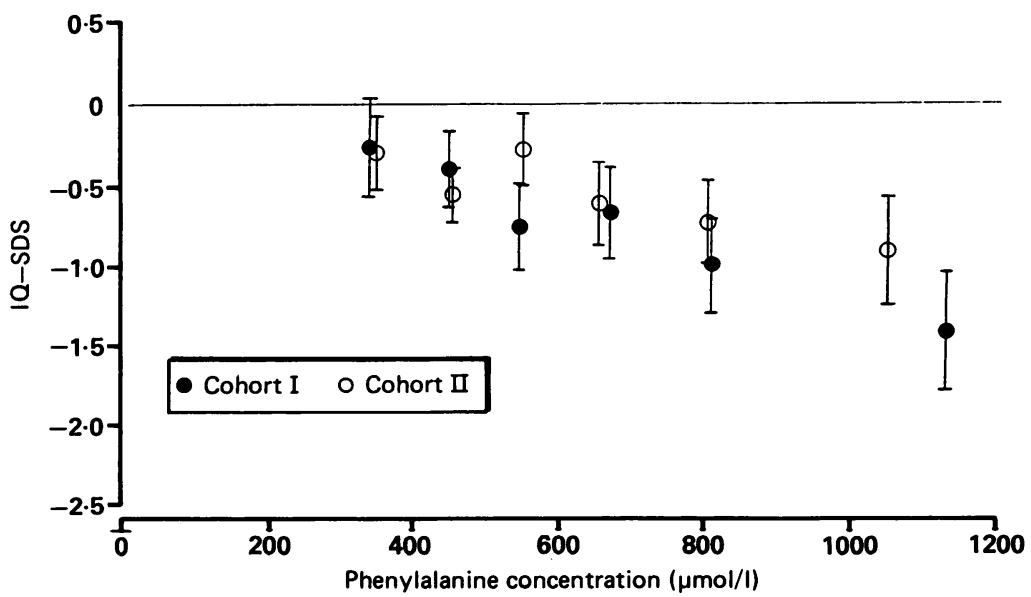

Figure 3 Association between IQ-SDS at 8 years and mean phenylalanine concentrations between 5 and 8 years after allowing for the influence of IQ-SDS at 4 years, mean phenylalanine between birth and 4 years, social class, type of phenylketonuria, and four factors related to diagnosis and early management (see methods) using regression analysis. ciation more fully. Social class, type of phenylketonuria, and the four factors relating to diagnosis and early management (see methods) were included in the regression equations, along with IQ-SDS at 4 years, average phenylalanine concentrations in the period $0-4$ years as a continuous variable, and average phenylalanine concentrations 5-8 years as a class variable.

In both cohorts IQ-SDS at 8 years was highly and directly correlated with IQ-SDS at 4 years (cohort I $F_{1,175}=96.9, p>0.0001$, cohort II $\left.F_{1,301}=140.0, p<0.0001\right)$. However, even after allowing for IQ-SDS at 4 years and all other factors, IQ-SDS at 8 years was independently and inversely associated with average phenylalanine control between 5 and 8 years (cohort $I_{5,175}=$ $4 \cdot 5, \mathrm{p}<0.0007$, cohort II $\mathrm{F}_{5,301}=2 \cdot 8, \mathrm{p}<0.016$ ). The means for IQ-SDS at 8, adjusted for the effects of the other covariates by regression, are plotted against mean phenylalanine in fig 3 . 
The trends were similar in both cohorts and linear. With the exceptions of a positive association with birth year in cohort I $\left(\mathrm{F}_{1,175}=5 \cdot 9, \mathrm{p}=\right.$ $0.016)$ and a negative association with phenylalanine control $0-4$ years in cohort II $\left(F_{1,301}=\right.$ $6.0, p=0.015)$ there were no further independent associations between IQ-SDS at 8 years and any other variables. Type of phenylketonuria had no independent influence on IQ-SDS once allowance was made for phenylalanine control.

Similar regression analyses were carried out to examine the association of IQ-SDS at ages $8,10,12$, and 14 years to mean phenylalanine concentrations in the period between assessments, now treated as a continuous linear variable, while controlling for the other factors. Thus at age 10 years IQ-SDS was regressed against average phenylalanine concentrations between ages 9-10, while controlling for: IQ-SDS at 8, phenylalanine concentrations between birth and 4 years and between 5 and 8 years, social class, type of phenylketonuria, and the four factors relating to diagnosis and early management. At 12 years phenylalanine control between 11 and 12 years was added to the equation and at 14 years IQ-SDS at 8 years was replaced by IQ-SDS at 10 years and phenylalanine control 13-14 years was added. An analysis of IQ-SDS at 4 years in the children also tested at 8 years was included for comparison, although no preceding IQ-SDS was available for inclusion in the analysis.

Estimates of the slopes of the regression lines at different ages are set out in table 3; these represent the effect on IQ-SDS of an $1000 \mu \mathrm{mol} / \mathrm{l}$ rise in phenylalanine. The results at 4 years were similar in both cohorts. At 8 years the slopes of the regression lines were somewhat less than at 4 years, particularly in cohort II, but were still significant. In cohort I after 8 years of age the association between IQ-SDS and mean phenylalanine control was no longer evident, though, in cohort II, a significant negative association between IQ-SDS and phenylalanine control persisted (though with a lower slope) and was still significant at 10 years.

From the slopes shown in table 3 it is predicted that for each $300 \mu \mathrm{mol} / 1$ rise in mean phenylalanine concentrations in the first 4 years of life, IQ at 4 years fell by 7 points in cohort I and 10 points in cohort II. After allowing for events up to 4 years, a rise of $300 \mu \mathrm{mol} / 1$ in mean phenylalanine concentrations between 5 and 8 years was associated with a fall in IQ at 8 years of 6 points in cohort $I$ and 4 points in cohort II. At 10 years IQ in cohort II fell 2 points for the same rise in phenylalanine. Similar results were obtained in regression models which examined each two year interval after 10 years, and also models which did not include adjustments for the variables related to events up to four years and phenylalanine concentrations before the preceding IQ.

\section{Discussion}

We have reported previously that intelligence at 4 years of age in children with phenylketonuria in the United Kingdom who were treated early was lower than expected in the general population, probably due to some degree of neurological impairment occurring despite dietary treatment, and that intelligence was inversely and linearly associated with average phenylalanine control from birth to 4 years. ${ }^{1 *}$ The present study shows that, even after taking events up to 4 years into account, intelligence at 8 years was still inversely associated with phenylalanine control between 5 and 8 years. A tendency for IQ to rise between 4 and 8 years in subjects with good control and to fall in those with poor control accounted for the lack of change in the mean IQ between the two ages.

After 8 years, despite a steep rise in blood phenylalanine concentrations, the association between intelligence and phenylalanine control was no longer evident in children born earlier. However, in those born later an inverse association between intelligence and phenylalanine control persisted to at least 10 years, although the association was less noticeable than at earlier ages. Later born subjects also differed from the earlier born in having higher IQs at all ages although, as discussed previously, ${ }^{1}$ our analysis does not fully explain this difference.

An explanation for the association we have documented between intelligence and phenylalanine control up to 8-10 years is that raised brain phenylalanine concentrations, via closely related biochemical events such as deficiency of neuronal amino acids ${ }^{9}$ and increased myelin turnover, ${ }^{10}$ exert an adverse, dose related effect on brain growth and development, greatest during early childhood and declining gradually thereafter. This interpretation is consistent with what is known about the natural history of the untreated condition ${ }^{7}$ and with previous reports that children deliberately placed on a normal diet at or before 8 years showed falls in $\mathrm{IQ}^{34}$ or in educational progress ${ }^{5}$ after the change in treatment. Our findings are also in agreement with those of the American Collaborative Study, which showed that lower IQ was associated with earlier age (up to 8 years) at which average phenylalanine concentrations reached 900 $\mu \mathrm{mol} / \mathrm{l}^{6}$

Nevertheless, an indirect contribution to the association between intelligence and hyperphenylalaninaemia cannot be ruled out. In our study the minority of subjects with non-classical phenylketonuria (defined as failure of blood phenylalanine concentrations to rise above 1200 $\mu \mathrm{mol} / \mathrm{l}$ during a period of dietary relaxation) did consistently better than those with the classical disorder with respect to both intelligence and phenylalanine control. This intellectual advantage in non-classical subjects could be fully accounted for by their better phenylalanine control. As a child grows older and dietary treatment is less strictly maintained, however, there is wider variation between patients in phenylalanine concentrations. It is possible that this increased variation provides an additional and more sensitive index of 'severity' than the other

* In our previous paper a lower figure was given of 'approximately 4 points for each $300 \mu \mathrm{mol} / 1$ rise in mean phenylalanine concentrations'; this was an error and should have read 'approximately 8 points for each $300 \mu \mathrm{mol} / /$ rise in mean phenylalanine concentrations' 
variables we have used and might, therefore, be an additional determinant of the adverse effects of phenylketonuria on the nervous system, associted with but not wholly dependent on phenylalanine control. Nevertheless, that the associations between intelligence and phenylalanine control after 4 years persisted after controlling for IQ at 4 years and the history of phenylalanine control, provides strong support for the view that phenylalanine excess exerts a direct and dose dependent effect on intellectual progress.

Whatever the correct explanation for associations between intelligence and dietary control at different ages, the results suggest a decline in the size of the association as children become older and particularly after 8 years, despite their much higher phenylalanine concentrations. This probably indicates that, by mid-childhood, maturation of the nervous system has advanced to a stage where the parameters of 'intelligence' have stabilised and are therefore less vulnerable to the biochemical effects of phenylketonuria.

The relatively stable intellectual state in older children does not preclude the development of other manifestations of neurological impairment. Four early treated subjects $(0.4 \%$ of register subjects aged over 12 years) are known to have developed new and major neurological problems (paraplegia and epilepsy) in adolescence or early adult life and lesions in the subcortical white matter were found on magnetic resonance imaging. ${ }^{11}$ The literature contains several other case reports of new neurological abnormalities developing in both late and early treated adolescents and young adults with phenylketonuria. ${ }^{12} 13$ In addition postmortem studies have documented signs of active demyelination $^{12}{ }^{14}$ as well as hypomyelination and reduced brain size. White matter changes on magnetic resonance imaging have also been reported in children without neurological deterioration but with a history of poor phenylalanine control. ${ }^{15}$

We conclude that optimal intelligence is unlikely to be achieved in children with phenylketonuria unless phenylalanine concentrations are mostly below $400 \mu \mathrm{mol} / 1$ throughout the first half of childhood. In children with severe classical phenylketonuria it is difficult to maintain phenylalanine concentrations within a very narrow range and such children are likely to be at a particular risk of intellectual impairement. Even though the changes of intellectual deterioration due to high phenylalanine concen- trations appear to diminish as the child grows older, in some individuals at least, phenylketonuria poses a lifelong hazard to the integrity of the nervous system. Patients with phenylketonuria will, therefore, have to be advised to continue a low phenylalanine diet indefinitely, despite the uncertainties and real practical difficulties involved. As subjects pass through adolescence and early adult life it will be important to continue monitoring progress so that more information can be obtained concerning the size of risk to the nervous system and the factors related to neurological deterioration.

The Medical Research Council (MRC) Steering Committee thank the parents and children for participating in the study, and the paediatricians, screening laboratory staff, and clinical and educational psychologists for supplying information to the Phenylketonuria Register. The register is financed jointly by the MRC and Department of Health, and is supervised by an MRC Steering Committee: Professor F Cockburn (chairman), Dr D Carson, Professor BE Clayton, Professor PJ Graham, Dr M Hally, Mr RD Jennings, Dr I Lister-Cheese, Mrs ME Lobascher, Dr I Smith, Dr I Sutherland, Professor AC Turnbull, and Professor OH Wolff.

I Smith I, Beasley MG, Ades AE. Intelligence and quality of dietary treatment in phenylketonuria. Arch Dis Child 1990, dietary treat
$65: 472-8$.

2 Smith I, Beasley M, Wolff OH, Ades AE. Behaviour disturbance in eight year old children with early treated phenylketonuria (PKU). 3 Pediatr 1988;112:403-8.

3 Cabalska B, Duczynska N, Borzymowska J, Zorska K, Koslacz-Folga A, Bozkova K. Termination of dietary treatment in phenylketonuria. Eur $\mathcal{F}$ Pediatr 1977;126:253-62.

4 Smith I, Lobascher ME, Stevenson JE, et al. Effect of stopping low-phenylalanine diet on intellectual progress of children with phenylketonuria. BMJ 1978;ii:723-6.

5 Koch R, Azen CG, Friedman EG, Williamson ML. Prelimin ary report on the effects of diet discontinuation in PKU. f Pediatr 1982;100:870-5.

6 Holtzman NA, Kronmal RA, van Doornick W, Azen C, Koch R. Effect of age at loss of dietary control on intellectual performance and behaviour in children with phenylketonuria. $N$ Engl $\mathcal{F}$ Med 1986;314:593-8.

7 Smith I. The hyperphenylalaninaemias. In: Lloyd JK Scriver CR, eds. Genetics and metabolic disease. Butterworths' International Medical Reviews. Pediatrics 5. London: Butterworth, 1985:166-209.

8 Wolff $\mathrm{OH}$, Smith I, Beasley M. Quelques limits de la classification et da la nomenclature des hyperphenylalaninemie. Arch Fr Pediatr 1987;44:635-8.

9 Pratt OE. A new approach to the treatment of phenylketonuria. F Ment Defic Res 1980;24:203-17.

10 Hommes FA, Eller GA, Taylor EH. Turnover of fast com ponents of myelin and myelin proteins in experimenta hyperphenylalaninaemia. Relevence to termination of dietary treatment. F Inherited Metab Dis 1982;5:21-7.

11 Thompson AJ, Smith I, Brenton D, et al. Neurological deterioration in young adults with phenylketonuria. Lancet 1990;336:602-5.

12 Malamud $N$. Neuropathology of phenylketonuria. 7 Neuropathol Exp Neurol 1966;25:254-68.

13 Villasana D, Butler IJ, Williams JC, Roongta SM. Neurological deterioration in adult phenylketonuria. $\mathcal{J}$ Inherited logical deterioration in ad
Metab Dis 1989;12:451-7.

14 Poser CM, van Bogaert L. Neuropathologic observations in phenylketonuria. Brain 1959;82:1-9.

15 Bick U. Fahrendorf G, Ludolph A, Ulirich K. MR imaging of the brain in patients with hyperphenylalaninaemia. 27th Annual Symposium of the Society for the Study of Inborn Errors of Metabolism, Munich 1989: PO23. SSIEM abstracts. Pinner: SSIEM, 1990. 